\title{
Control of mRNA translation preserves endoplasmic reticulum function in beta cells and maintains glucose homeostasis
}

\author{
Donalyn Scheuner ${ }^{1}$, Dirk Vander Mierde ${ }^{2}$, Benbo Song ${ }^{1}$, Daisy Flamez ${ }^{3,6}$, John W M Creemers ${ }^{4}$, \\ Katsura Tsukamoto ${ }^{2}$, Mark Ribick ${ }^{5}$, Frans C Schuit ${ }^{2} \&$ Randal J Kaufman $^{1,5}$
}

Type 2 diabetes is a disorder of hyperglycemia resulting from failure of beta cells to produce adequate insulin to accommodate an increased metabolic demand. Here we show that regulation of mRNA translation through phosphorylation of eukaryotic initiation factor 2 (elF2 $\alpha$ ) is essential to preserve the integrity of the endoplasmic reticulum (ER) and to increase insulin production to meet the demand imposed by a high-fat diet. Accumulation of unfolded proteins in the ER activates phosphorylation of elF2 $\alpha$ at Ser51 and inhibits translation. To elucidate the role of this pathway in beta-cell function we studied glucose homeostasis in Eif2s $1^{\mathrm{tm} 1 \mathrm{Rjk}}$ mutant mice, which have an alanine substitution at Ser51. Heterozygous (Eif2s ${ }^{+/ \mathrm{tm} 1 \mathrm{Rjk})}$ mice became obese and diabetic on a high-fat diet. Profound glucose intolerance resulted from reduced insulin secretion accompanied by abnormal distension of the ER lumen, defective trafficking of proinsulin, and a reduced number of insulin granules in beta cells. We propose that translational control couples insulin synthesis with folding capacity to maintain ER integrity and that this signal is essential to prevent diet-induced type 2 diabetes.

Type 2 or non-insulin-dependent diabetes mellitus is a major cause of morbidity and mortality worldwide that is influenced by genetic factors, diet and exercise ${ }^{1}$. Insulin resistance often underlies the disease; however, diabetes results from failure of pancreatic beta cells to increase insulin production and compensate for the resistance. The recent epidemic of type 2 diabetes suggests that environment is a major determinant of disease, and a high concordance rate in monozygotic twins affirms the significance of genetic predisposition. The hallmark of pancreas dysfunction in type 2 diabetes is diminished glucoseresponsive insulin secretion, which is regulated by signals derived from mitochondrial metabolism ${ }^{2}$. To maintain adequate intracellular insulin stores, beta cells must adapt their acute and chronic rates of insulin biosynthesis to compensate for insulin release ${ }^{3}$. Biosynthesis of insulin is controlled acutely at the translational level ${ }^{4}$, through mechanism(s) that are still incompletely understood. General mRNA translation in beta cells is stimulated by glucose, but, additionally, translation of mRNA encoding insulin is preferentially upregulated ${ }^{5}$, probably through mRNA-specific mechanisms $s^{6}$. Chronic elevation in extracellular glucose concentration further stimulates the synthesis of insulin by increasing expression of the mRNAs encoding preproinsu$\operatorname{lin}^{7-9}$ and additional components of the secretory pathway to support processing, transport and glucose-regulated secretion of insulin ${ }^{10,11}$.
Type 2 diabetes results from failure of beta cells to adequately adapt to the increasing demand for insulin production.

An important level of translational control of gene expression is regulation of initiation, which is a complex process serving to assemble ribosomal subunits on mRNA and to promote recognition of an authentic AUG initiation codon for the start of polypeptide chain synthesis. The initiation factor eIF2 forms a ternary complex with initiator methionyl-tRNA and GTP and is essential for initiation codon selection. Phosphorylation at Ser51 on the alpha subunit of eIF2 inhibits ternary complex formation and is a fundamental mechanism that limits translation initiation in all eukaryotic cells ${ }^{12}$. The mammalian genome encodes four protein kinases that are dedicated to phosphorylate eIF2 $\alpha$ at Ser51: (i) the heme-regulated inhibitor kinase HRI, which coordinates the rate of globin synthesis with heme availability $^{13}$; (ii) the double-stranded RNA-activated kinase PKR, which is a component of the interferon antiviral response to arrest viral mRNA translation ${ }^{14}$; (iii) the general control of amino acid metabolism kinase GCN2, which couples translation with available amino acid stores $^{15}$; and (iv) the ER kinase PERK, which reduces the rate of mRNA translation in response to overloading the protein-folding capacity in the $\mathrm{ER}^{16}$. PERK activation is one of three known signaling pathways constituting a translational and transcriptional response to the

\footnotetext{
${ }^{1}$ Howard Hughes Medical Institute, University of Michigan, 1150 W. Medical Center Drive, Ann Arbor, Michigan 48109, USA. ${ }^{2}$ Gene Expression Unit, Department of Molecular Cell Biology, Katholieke Universiteit Leuven, Herestrat 49, B-3000, Leuven, Belgium. ${ }^{3}$ Diabetes Research Center, Vrije Universiteit Brussel, Laarbeeklaan 103, B-1090, Brussels, Belgium. ${ }^{4}$ Department Menselijke Erfelijkheid, Katholieke Universiteit Leuven, Leuven, and Vlaams Interuniversitiair Instituut voor Biotechnologie, Herestrat 49, B-3000, Brussels, Belgium. ${ }^{5}$ Department of Biological Chemistry, University of Michigan, 1150 W. Medical Center Drive, Ann Arbor, Michigan 48109, USA. 6 Present address: Laboratory of Experimental Medicine, Université Libre de Bruxells, Route de Lennick 808 , B-1070, Brussels, Belgium. Correspondence should be addressed to F.C.S. (frans.schuit@med.kuleuven.be) or R.J.K. (kaufmanr@umich.edu).
} 
a

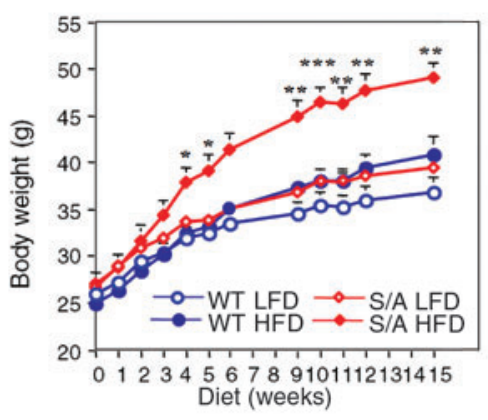

b

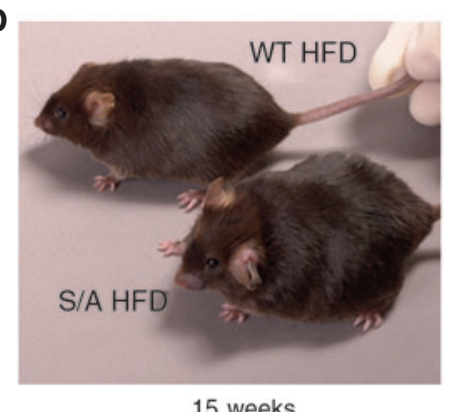

15 weeks
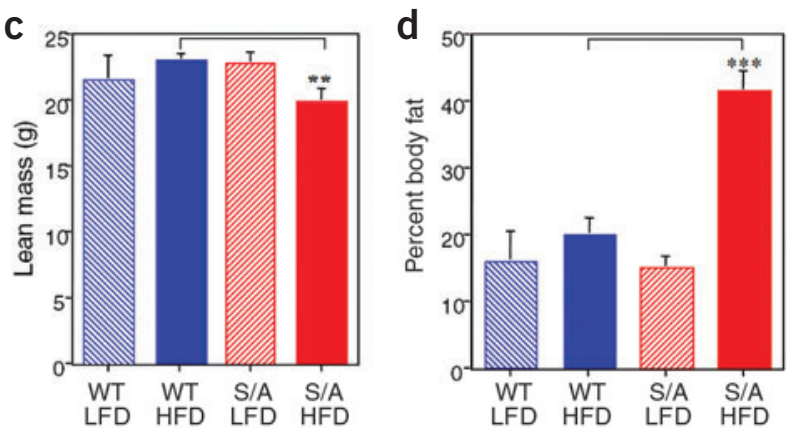

Figure 1 HFD produces obesity in Eif2s1 $1^{+/ t m 1 R j k}$ mice. (a) Eif2s $1^{+/ t m 1 R j k} \mathrm{HFD}$-fed animals gain significantly more weight than wild-type HFD-fed mice. Weight gain was measured for wild-type and Eif2s $1^{+/ t m 1 R j k}$ male mice on LFD or HFD. Data are mean \pm s.e.m., $n=6-8$ male mice per condition. Eif2s $1^{+/ t m 1 R j k} \mathrm{HFD}$ versus wild-type HFD, ${ }^{*} P<0.05,{ }^{* *} P<0.01,{ }^{* * *} P<0.001$. (b) Representative male wild-type and Eif2s $1^{+/ t m 1 R j k}$ mice photographed after 15 weeks of HFD. The experimental groups of animals did not differ in nose-to-tail length at age 24 weeks. Wild-type LFD, $10.2 \pm 0.1$; Eif2s $1^{+/ t m 1 R j k}$ LFD, $10.1 \pm 0.1$; wild-type HFD, $10.1 \pm 0.2$; Eif2s $1^{+/ \mathrm{tm} 1 \mathrm{Rjk}}$ HFD, $10.2 \pm 0.2 \mathrm{~cm}, n=4-6$ animals per condition. (c,d) The fat mass in Eif2s $1^{+/ t m 1 R j k}$ HFD-fed animals is significantly increased compared to wild-type HFD-fed mice. Lean mass and percentage of body fat for wild-type and Eif2s $1^{+/ t m 1 R j k}$ male mice on LFD or HFD for 7 weeks. Animals were 16 weeks of age at the start of diet feeding. Dexa-scanning analysis was performed as described in Supplementary Methods online. Data are mean \pm s.e.m., $n=4-6$ mice per condition. ${ }^{* *} P \leq 0.01,{ }^{* *} P \leq 0.001$. (e) Food intake (Kcal/d) is increased in the HFD-fed wildtype and mutant animals. Food intake for wild-type and Eif2s $1^{+/ \mathrm{m} 1 \mathrm{Rjk}}$ male mice was measured during weeks 1, 2, 3 and 6 of the LFD and HFD, as in a. Data are mean \pm s.e.m. of the four independent intake measurements, $n=8$ animals per condition. ${ }^{* * *} P \leq 0.001$. WT, wild-type; S/A, Eif2s $1^{+/ t m 1 R j k}$ genotype.

accumulation of unfolded proteins in the ER that is known as the unfolded protein response (UPR) ${ }^{17}$. A classical component of the UPR is association of unfolded proteins with the ER lumenal chaperone BiP and subsequent transcriptional activation of the gene encoding $\mathrm{BiP}^{18,19}$. Increased expression of $\mathrm{BiP}$ improves ER function by influencing a variety of processes including protein translocation, folding, solubility and degradation, and prevents further activation of UPR-sensing pathways and apoptosis ${ }^{20,21}$. Recently, homozygous mutations in the gene encoding the eIF2 $\alpha$ kinase PERK were shown to cause beta-cell death and infancy-onset diabetes in the human autosomal recessive disease Wollcot-Rallison syndrome $e^{22,23}$ and in genetically engineered mice $^{24}$. In contrast, beta-cell defects were not observed in mice lacking functional genes encoding HRI, PKR or GCN2 (refs. 13, 25, 26). In addition, mouse embryos that harbor homozygous mutation of Eif2s $1^{\text {tm1Rjk }}$ at the phosphorylation site in eIF2 $\alpha$ die within $24 \mathrm{~h}$ after birth and show a severe beta-cell deficiency detectable in late-stage embryos ${ }^{27}$. These results support the notion that PERK-mediated phosphorylation of eIF $2 \alpha$ is crucial for beta-cell function. To test this hypothesis in vivo, we investigated the phenotype of heterozygous (Eif $2 s 1^{+/ \mathrm{tm} 1 \mathrm{Rjk}}$ ) mice fed a low-fat diet (LFD) or $45 \%$ high-fat diet (HFD). The results elucidate a new mechanism for an insulin secretory defect in beta cells

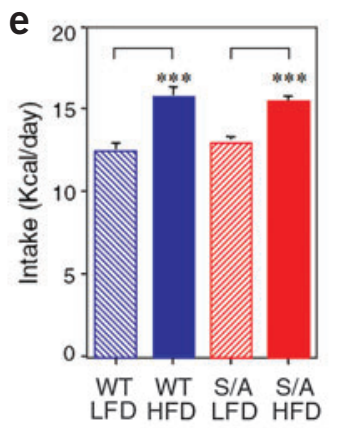

that results in type 2 diabetes. The nature of beta-cell failure in this model is supported by electron microscopy of pancreas tissue and ex vivo studies of isolated islets that show a combination of secretory incompetence, failure to attenuate translation and increased association of proinsulin with $\mathrm{BiP}$ in the $\mathrm{ER}$ compartment.

\section{RESULTS \\ Eif2s $1^{+/ \mathrm{tm} 1 \mathrm{Rjk}}$ mice become obese on a HFD}

In the absence of any environmental challenge, heterozygous Eif2s $1^{+/ \mathrm{tm} 1 \mathrm{Rjk}}$ mice are phenotypically normal. But 10-12-week-old male Eif2s $1^{+/ \mathrm{tm} 1 \mathrm{Rjk}}$ animals gained significantly more weight than wildtype $\left(\right.$ Eif $\left.2 s 1^{+/+}\right)$littermate mice when fed a HFD (Fig. 1a,b). The increased weight gain did not result from an increase in animal size, as the nose-to-tail measurement did not differ between any of the animal groups studied (Fig. 1b). Female Eif2s $1^{+/ \mathrm{tm} 1 \mathrm{Rjk}}$ mice also showed increased weight gain in comparison to wild-type littermates, although it was delayed approximately 5 weeks compared to the male mice (data not shown). Increased weight gain was observed in Eif $2 s 1^{+/ \mathrm{tm} 1 \mathrm{Rjk}}$ animals compared to wildtype animals regardless of whether they were placed upon HFD shortly after weaning (data not shown) or after the age of 4-5 months (data not shown and Fig. 1c,d). Although the background strain of $\mathrm{C} 57 \mathrm{Bl} / 6 \mathrm{~J}$ is susceptible to weight gain upon long-term HFD, the Eif2s $1^{+/ \mathrm{tm} 1 \mathrm{Rjk}}$ mice under all conditions of study were predisposed to a greater weight gain than wild-type littermates. At 7 weeks of diet exposure, body fat was increased markedly in every Eif2s $1^{+/ \mathrm{tm} 1 \mathrm{Rjk}}$ HFD-fed animal, with an average body fat of $40 \%$, which accounted for the increased weight gain (Fig. 1d). Histological examination indicated moderate microvesicular steatosis in the central zone of the liver lobules in both wild-type and mutant HFD-fed mice. Consistent with the obesity phenotype observed, macrovesicular steatosis was greatly enhanced in the peripheral zone of the lobules throughout the entire liver of HFD-fed Eif $2 s 1^{+/ \mathrm{tm} 1 \mathrm{Rjk}}$ mice in comparison to HFD-fed wild-type Eif $2 s 1^{+/+}$mice (Supplementary Fig. 1 online).

Studies of food intake and energy metabolism showed that the cause of adiposity in Eif2s $1^{+/ \mathrm{tm} 1 \mathrm{Rjk}}$ animals was a reduced expenditure of energy. Upon the start of the HFD, there were slight and comparable increases in food consumption for both wild-type and mutant strains of mice that were consistent with previous studies ${ }^{28}$ (Fig. 1e). But oxygen consumption $\left(\mathrm{VO}_{2}\right)$ and carbon dioxide $\left(\mathrm{CO}_{2}\right)$ production, were significantly decreased in HFD-fed Eif2s $1^{+/ \mathrm{tm} 1 \mathrm{Rjk}}$ mice compared to HFD-fed wild-type mice (Supplementary Fig. 2 online). The differences could account for the increased weight gain in the mutant mice by comparison to other mouse models of obesity ${ }^{29}$. During the acute HFD, only wild-type mice compensated for the caloric excess through increased energy expenditure (increased $V \mathrm{O}_{2}$ ), a process requiring $\beta$ adrenergic receptor signaling ${ }^{30}$. Increased adipose mass may also be 
exacerbated by the mild hyperinsulinemia ${ }^{31}$ observed in Eif $2 s 1^{+/ \mathrm{tm} 1 \mathrm{Rjk}}$ HFD-fed mice (Supplementary Fig. 2 online). As tumor necrosis factor (TNF)- $\alpha$ signals through PKR and eIF2 $\alpha$ phosphorylation, it is also possible that signaling through this cachexia hormone is impaired in Eif2s $1^{+/ \mathrm{tm} 1 \mathrm{Rjk}}$ mice $^{32}$.

Analysis of serum samples identified a number of metabolic parameters consistent with a 'diabesity' phenotype in the mutant mice including hyperleptinemia, mild hyperinsulinemia and elevated fasting blood glucose after 7 weeks of HFD (Supplementary Fig. 2 online). Serum insulin levels were further elevated upon longer-term exposure to HFD (at 35 weeks, Eif2s $1^{+/+}$HFD-fed 2.9 \pm 0.6 , Eif2s $1^{+/ \mathrm{tm} 1 \mathrm{Rjk}} \mathrm{HFD}$-fed $\left.5.1 \pm 0.5 \mathrm{ng} / \mathrm{ml}, P<0.05\right)$. The mild hyperglycemia, enhanced steatosis and hyperinsulinemia of the heterozygous Eif2s $1^{+/ \mathrm{tm} 1 \mathrm{Rjk}} \mathrm{HFD}$-fed animals suggest a degree of insulin resistance, possibly liver insulin resistance, which is uncompensated.

\section{Glucose intolerance and impaired insulin release in Eif2s $1^{+/ t m 1 R j k}$ HFD mice}

Glucose homeostasis was assessed in vivo through glucose- and insulintolerance testing, and ex vivo by measuring insulin release from isolated islets. Wild-type and Eif2s $1^{+/ \mathrm{tm} 1 \mathrm{Rjk}}$ mice fed a LFD showed no difference in glucose tolerance (Fig. 2a). Aging up to 12 months did not provoke glucose intolerance in Eif $2 s 1^{+/ \mathrm{tm} 1 \mathrm{Rjk}}$ animals fed a standard diet (data not shown). Short-term exposure of wild-type mice to a HFD containing $45 \%$ fat caused only a minor change in glucose tolerance (Fig. 2a). In contrast, littermate Eif2s $1^{+/ t m 1 R j k}$ mice fed a HFD for 5 weeks developed severe glucose intolerance (Fig. 2a). Longer exposure of the animals to diet treatment induced modest glucose intolerance in wild-type mice and further compromised glucose homeostasis in the Eif2s $1^{+/ \mathrm{tm} 1 \mathrm{Rjk}}$ HFD-fed mice (Fig. 2b). Serum fatty acid levels did not differ between wild-type and mutant mice (Supplementary Fig. 2 online), suggesting that the mutation alters the sensitivity to fatty acid-induced intolerance rather than directly altering fatty acid levels. In addition, the presence of the Eif2s $1^{\text {tm1Rjk }}$ allele in leptin receptor-deficient mice $(\operatorname{Lepr} \mathrm{db} / \mathrm{db})$ background significantly decreased glucose tolerance (Supplementary Fig. 3 online). Therefore, reduced eIF2 $\alpha$ phosphorylation predisposes to diabetes when combined with either a dietary stress or a genetic determinant of diabetes, such as the Lepr $\mathrm{db}^{\mathrm{d} / \mathrm{db}}$ genotype.

An insulin-tolerance test showed that LFD-fed wild-type and LFD-fed Eif2s $1^{+/ \mathrm{tm} 1 \mathrm{Rjk}}$ mutant mice had similar rates of glucose clearance (Fig. 2c). Moreover, glucose clearance was comparably impaired in HFD-fed wild-type and HFD-fed Eif2s $1^{+/ \mathrm{tm} 1 \mathrm{Rjk}}$ mice (Fig. 2c), supporting that glucose intolerance in HFD-fed heterozygous Eif $2 \mathrm{~s} 1^{+/ \mathrm{tm} 1 \mathrm{Rjk}}$ mice was not the result of a major difference in insulin responsiveness for glucose disposal. But the HFD-fed Eif2s $1^{+/ \mathrm{tm} 1 \mathrm{Rjk}}$ mice were defective in the early phase of insulin secretion in response to intraperitoneal glucose challenge (Fig. 2d,e). The data for female animals is shown because the elevated basal levels of insulin in the HFD-fed males made the absence of a first phase of insulin release response more difficult to interpret. Thus, we propose that an insulin secretion defect is provoked by the combination of a HFD and the mutation in eIF2 $\alpha$ and that this defect is central to the glucose intolerance and diabetic phenotype. a

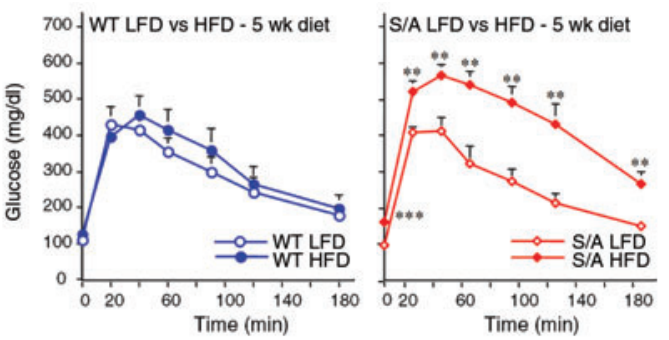

b

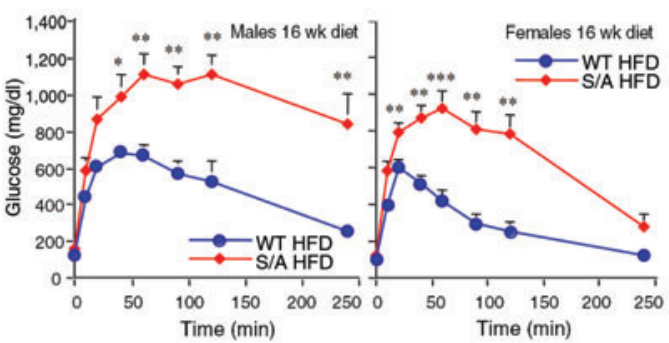

C

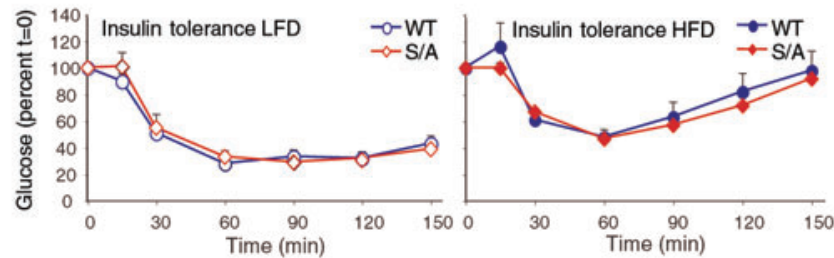

d

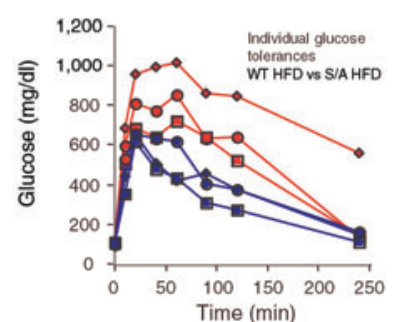

e
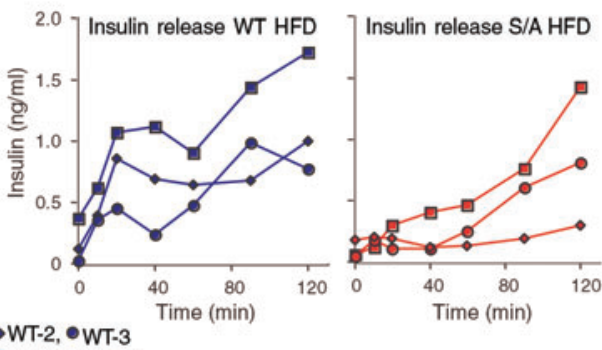

$\square S / A-1,0 S / A-2, \bullet S / A-3$

Figure 2 Eif2s $1^{+/ t m 1 R j k}$ mice show glucose intolerance and a defect in phase 1 insulin secretion. Glucose and insulin tolerance methods are described in

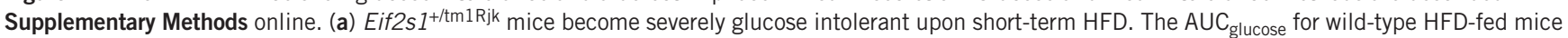
(3.2 $\pm 0.4 \mathrm{~mol} / \mathrm{L} / 180 \mathrm{~min})$ versus wild-type LFD-fed mice $(2.9 \pm 0.3 \mathrm{~mol} / \mathrm{L} / 180 \mathrm{~min}$ ) shows a $10 \%$ increase as a result of HFD feeding (left). The AUC $\mathrm{glucose}$ for Eif2s $1^{+/ \mathrm{m} 1 \mathrm{Rjk}} \mathrm{HFD}$-fed mice $(4.4 \pm 0.3 \mathrm{~mol} / \mathrm{L} / 180 \mathrm{~min})$ versus LFD-fed mice $(2.6 \pm 0.2 \mathrm{~mol} / \mathrm{L} / 180 \mathrm{~min})$ shows a $66 \%$ increase resulting from a HFD (right; $P<0.001$ ). Data are mean \pm s.e.m., $n=6-8$ mice per condition; LFD versus HFD, ${ }^{* *} P<0.01,{ }^{* * *} P<0.001$. The mild fasting hyperglycemia of Eif2s $1^{+/ t m 1 R j k}$ HFD-fed mice is apparent here because of the expanded scale of the $y$-axis. (b) Eif2s $1^{+/ t m 1 R j k}$ mice become profoundly glucose intolerant upon long-term HFD. The $\mathrm{AUC}_{\text {glucose }}$ of Eif2s1/tm1Rjk mice was increased by $98 \%$ and $132 \%$ in males and females, respectively, versus wild-type littermates of the same sex treated for the same period with HFD ( $P<0.001$ for both comparisons). Data are mean \pm s.e.m., $n=6$ mice per condition. Eif2s ${ }^{+/ t m 1 R j k ~ H F D-f e d ~}$ versus wild-type HFD-fed, ${ }^{*} P<0.05,{ }^{* *} P<0.01,{ }^{* * *} P<0.001$. (c) Insulin-stimulated glucose clearance is similar in Eif2s ${ }^{+/ t m 1 R j k}$ and wild-type animals. Data are mean \pm s.e.m., $n=4-8$. (d,e) The glucose intolerance observed in Eif2s $1^{+/ t m 1 R j k}$ mice (d) is coincident with impaired insulin release. Glucose tolerance (d) and time course of plasma insulin (e) for individual female wild-type (WT-1, WT-2, WT-3) and Eif2s1+/tm1Rjk (S/A-1, S/A-2, S/A-3) mice on HFD diet. WT, wild-type; S/A Eif2s $1^{+/ t m 1 R j k}$ genotype. 
To elucidate the molecular basis of the insulin secretion defect, islets were isolated from wild-type and Eif $2 s 1^{+/ \mathrm{tm} 1 \mathrm{Rjk}}$ mice to study the kinetics of glucose-induced insulin release in a dynamic perifusion system ${ }^{33}$. Although the insulin content per islet was reduced $40 \%$ in the HFD-fed Eif $2 \mathrm{~s} 1^{+/ \mathrm{tm} 1 \mathrm{Rjk}}$ mice, the islets did not appear smaller and the insulin content of the pancreas was only slightly reduced because there was a corresponding increase in islet number per pancreas, as often occurs in compensation under conditions of obesity (Table 1). To evaluate the secretion efficiency of the islet beta cells, insulin release was normalized to islet insulin content. The basal insulin secretion rate from islets of Eif $2 \mathrm{~s} 1^{+/ \mathrm{tm} 1 \mathrm{Rjk}}$ mice was elevated under both diet conditions and it was $40 \%$ higher in islets of HFD-fed heterozygous Eif $2 s 1^{+/ \mathrm{tm} 1 \mathrm{Rjk}}$ mice in comparison to islets from HFD-fed wild-type mice $(P=0.02)$. Islets from LFD-fed Eif2s $1^{+/ \mathrm{tm} 1 \mathrm{Rjk}}$ mice showed a normal insulin secretory response to glucose and arginine, either when studied directly after islet isolation (data not shown) or after overnight tissue culture (Fig. 3a,b). On the contrary, stimulus-induced secretion was markedly reduced in islets from HFD-fed Eif2s1 $1^{+/ \mathrm{tm} 1 \mathrm{Rjk}}$ mice (Fig. 3a,b). Because of both increased basal and decreased nutrient-induced secretion, the stimulated insulin release above basal (either by glucose alone or glucose plus arginine) was three to five times lower in islets from HFD-fed Eif2s $1^{+/ \mathrm{tm} 1 \mathrm{Rjk}}$ mutant mice in comparison to those of HFD-fed wild-type mice (Fig. 3b).

In summary, although there is compensation to maintain total pancreatic insulin content in HFD-fed Eif2s $1^{+/ \mathrm{tm} 1 \mathrm{Rjk}}$ mice (Table 1), the insulin content per islet is reduced, and secretory responsiveness is diminished. This defect in insulin secretion studied ex vivo is consistent with the glucose intolerance and reduced secretion of insulin observed in vivo.

\section{HFD-fed Eif2s $1^{+/ t m 1 R j k}$ beta cells show abnormal ER}

To provide insight into the mechanism for the reduced insulin secretion, we examined the ultrastructure of pancreata. Distension of the ER compartment was not present in HFD-fed wild-type mice (Fig. 4a), whereas there was a profound distension of the ER compartment in beta cells from HFD-fed Eif2s $1^{+/ \mathrm{tm} 1 \mathrm{Rjk}}$ mice (Fig. 4b). The ER compartment was not distended in beta cells from LFD-fed Eif $2 s 1^{+/ \mathrm{tm} 1 \mathrm{Rjk}}$ mice

(Fig. 4c). The distended ER was associated with accumulation of electron-dense material and was observed in the majority of beta cells from HFD-fed Eif2s $1^{+/ \mathrm{tm} 1 \mathrm{Rjk}}$ mice (48 of 71, 68\%). Several observations support the validity of the ER distension observed in beta cells

Table 1 Insulin content and glucose-stimulated total protein synthesis in islets

\begin{tabular}{|c|c|c|c|c|}
\hline & \multicolumn{2}{|c|}{ Wild-type islets } & \multicolumn{2}{|c|}{ Eif2s $1^{+/ \mathrm{tm} 1 \mathrm{Rjk}}$ islets } \\
\hline & LFD & HFD & LFD & HFD \\
\hline \multicolumn{5}{|c|}{ Insulin/ islet ${ }^{a}$ (ng/islet) } \\
\hline$n=4$ & $92 \pm 15$ & $70 \pm 13$ & $70 \pm 7$ & $42 \pm 3^{*}$ \\
\hline \multicolumn{5}{|c|}{ Number of islets/pancreas ${ }^{a}$} \\
\hline$n=7-8$ & $134 \pm 25$ & $156 \pm 24$ & $165 \pm 60$ & $276 \pm 73^{* *}$ \\
\hline \multicolumn{5}{|c|}{ Insulin/pancreas ${ }^{a}$ ( $\left.\mu g / g\right)$} \\
\hline$n=3-4$ & $741 \pm 66$ & $848 \pm 63$ & $827 \pm 85$ & $748 \pm 186$ \\
\hline [Glucose] (mM) & \multicolumn{4}{|c|}{ Total protein synthesis $\left(\mathrm{fmol}\left[{ }^{3} \mathrm{H}\right]\right.$-tyrosine/h/islet) ${ }^{\mathrm{b}}$} \\
\hline 1 & $75 \pm 15$ & $119 \pm 29$ & $94 \pm 32$ & $126 \pm 41$ \\
\hline 10 & $433 \pm 41^{*}$ & $376 \pm 63^{*}$ & $357 \pm 55^{*}$ & $524 \pm 18^{*, * *}$ \\
\hline
\end{tabular}

Mice were killed for collagenase islet isolation after 13-15 weeks of low-fat diet (LFD) or high-fat diet (HFD). The number of islets isolated per pancreas and insulin content per islet or per pancreas is shown as mean \pm s.e.m.; ${ }^{*} P=0.02$ Eif2s1 ${ }^{+/ t m 1 R j k}$ HFD-fed versus Eif2s $1^{+/ t m 1 R j k}$ LFD-fed mice. ${ }^{* *} P=0.0002$ Eif2s $1^{+/ t m 1 R j k}$ HFD-fed versus wild-type LFD-fed mice. ' $/$ slets were preincubated for $1 \mathrm{~h}$ at $1 \mathrm{mM}$ glucose, followed by $1 \mathrm{~h}$ incubation at 1 or $10 \mathrm{mM}$ glucose in the presence of $50 \mu \mathrm{Ci}$ of ${ }^{3} \mathrm{H}$-labeled tyrosine. Data are means \pm s.e.m. of three independent experiments. Significant $\left({ }^{*} P \leq 0.02\right)$ glucose stimulation of translation was observed within all four experimental groups. Glucose-induced rates of translation in HFD-fed Eif2s $1^{+/ \mathrm{tm} 1 \mathrm{Rjk}}$ islets were $50 \%$ higher than those observed in LFD-fed Eif2s $1^{+/ \mathrm{tm} 1 \mathrm{Rjk}}$ islets $\left({ }^{*} P<0.05\right)$. from HFD-fed Eif2s $1^{+/ \mathrm{tm} 1 \mathrm{Rjk}}$ mice. First, the mitochondria and other intracellular organelles of the beta cells had a normal appearance. Second, the ER distension was detected in the beta cells, and not in adjacent islet non-beta cells or in surrounding acinar cells. Third, the subcellular abnormality was diet specific and strain specific, as it was not observed in samples from LFD-fed animals or from HFD-fed wildtype mice. Furthermore, we analyzed the ultrastructure of pancreata from wild-type embryos shortly before birth (Fig. 4d) and identified extreme ER distension in the beta of homozygous Eif2s1 $1^{+/ \mathrm{tm} 1 \mathrm{Rjk}}$ embryos (Fig. 4e). The distension of ER in beta cells of HFD-fed Eif $2 s 1^{+/ \mathrm{tm} 1 \mathrm{Rjk}}$ mice was similar (though less severe) to the changes observed in beta cells from Eif2s $1^{+/ \mathrm{tm} 1 \mathrm{Rjk}}$ mice (Fig. 4e). In addition, there were $75 \%$ fewer granules present in beta cells with severe ER distension (defined as the point when ER luminal area is $70 \%$ of the cytosolic area; Fig. 4 b), consistent with the reduced insulin content per islet. These findings suggest that alterations in the structure, and possibly function, of the ER in beta cells of HFD-fed Eif2s $1^{+/ \mathrm{tm} 1 \mathrm{Rjk}}$ mice may be associated with secretory dysfunction and reduced biogenesis of insulin granules.

These data advocate that Eif2s $1^{+/ \mathrm{tm} 1 \mathrm{Rjk}}$ mice have a fundamental structural and functional defect in beta cells that predisposes them to fail upon the stress of a HFD and increased demand for insulin production. Although, the beta-cell failure could be driven by the concurrent obesity of these animals, the following observations support that this is not the case. First, HFD-fed mutant females show delayed weight , yet they developed glucose intolerance to a similar degree as males ance versus individual weight gain in Eif2s $1^{+/ \mathrm{tm} 1 \mathrm{Rjk}} \mathrm{HFD}$-fed male mice did not detect a significant correlation (correlation coefficient $r^{2}=0.16$; $>0.09$ at 5 weeks of HFD; Supplementary Fig. 4 online). Third, the abnormally distended ER, detected in HFD-fed Eif2s $1^{+/ \mathrm{tm} 1 \mathrm{Rjk}}$ animals, absence of any nutrient stress or obesity (Fig. 4). Finally, an abnormally distended beta-cell ER has not been observed in the $o b / o b$ mouse $^{34}$, a well-known model of genetically determined obesity in which the glu-

\section{Proinsulin binds BiP in Eif2s $1^{+/ t m 1 R j k}$ HFD mice}

The distended ER and insulin secretion defect suggested that a defect exists in proinsulin trafficking in the HFD-fed Eif $2 s 1^{+/ \mathrm{tm} 1 \mathrm{Rjk}}$ mice. As phosphorylation of eIF $2 \alpha$ inhibits translation initiation, islets from Eif $2 s 1^{+/ t m 1 R j k}$ mice may not properly attenuate proinsulin so that translation exceeds the capacity of the ER to fold and process proinsulin. In beta cells, low extracellular glucose $(<3 \mathrm{mM})$ represses translation and derepression occurs when the glucose level exceeds $3 \mathrm{mM}^{5}$. Therefore, we examined the effect of glucose on translation rates in wild-type and mutant islets. Translation rates in islets from LFD-fed animals were similar in the presence of $1 \mathrm{mM}$ glucose and increased approximately $400-500 \%$ in the presence of $10 \mathrm{mM}$ glucose (Table 1). Translation rates in the presence of high glucose were similar in islets from LFD-fed and HFD-fed wild-type mice. In contrast, translation rate was modestly increased in islets from Eif2s $1^{+/ \mathrm{tm} 1 \mathrm{Rjk}}$ HFD-fed mice. Thus, under conditions of elevated glucose and a HFD, phosphorylation of eIF $2 \alpha$ is required to limit protein translation and prevent ER overload. 
The morphological observations and the translation rates are evidence that a chronically elevated rate of mRNA translation in beta cells from HFD-fed Eif2s $1^{+/ \mathrm{tm} 1 \mathrm{Rjk}}$ mice may exceed the capacity of the ER to fold proinsulin and therefore impair anterograde transport of proinsulin to the Golgi compartment. To investigate whether the increased translation is associated with defective protein trafficking, we examined proinsulin biosynthesis using a pulse-chase metabolic-labeling experiment. Freshly isolated islets were pulse-labeled for $30 \mathrm{~min}$ with $\left[{ }^{35} \mathrm{~S}\right]$-methionine followed by chase for $1 \mathrm{~h}$ at $10 \mathrm{mM}$ glucose to assess the conversion of newly synthesized proinsulin into insulin. The existence and abundance of unfolded, newly synthesized proinsulin in the ER compartment was assessed by immunoprecipitation of the labeled islet extracts with a BiP-specific antibody. Similar amounts of newly synthesized BiP were immunoprecipitated from islets of both HFD-fed wild-type and mutant mice. Notably, newly synthesized proinsulin coimmunoprecipitated with $\mathrm{BiP}$ in the four experimental groups (Fig. 5a). The presence of the HFD alone or the Eif2s $1^{\text {tm1Rjk }}$ mutation alone increased the amount of proinsulin that coimmunoprecipitated with BiP. But the amount of labeled proinsulin associated with $\mathrm{BiP}$ was most abundant in the HFD-fed Eif2s $1^{+/ \mathrm{tm} 1 \mathrm{Rjk}}$ islets. Quantification showed that $18 \%$ of unprocessed proinsulin was associated with BiP in islet extracts of LFD-fed wild-type animals, whereas $76 \%$ was associated with BiP in extracts of HFD-fed Eif2s $1^{+/ \mathrm{tm} 1 \mathrm{Rjk}}$ mice. No other labeled proteins were detected that coimmunoprecipitated with BiP, excluding nonspecific interactions during the experiment. Immunoprecipitation of the prohormone convertase PC2 showed that similar amounts of islet extract were analyzed in these experiments. A second immunoprecipitation of these extracts with (pro)insulin-specific antibody was performed to detect 'free' proinsulin that was not in association with $\mathrm{BiP}$ and to also monitor the production

a

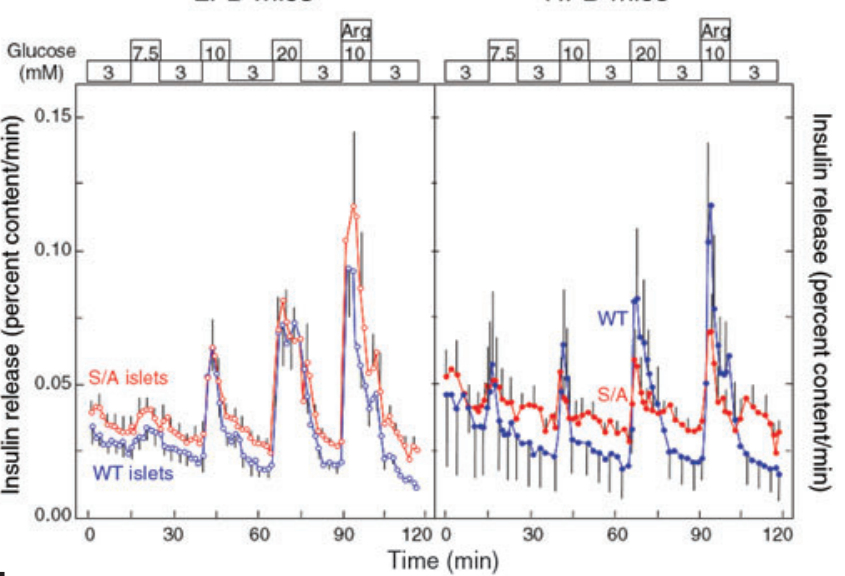

b

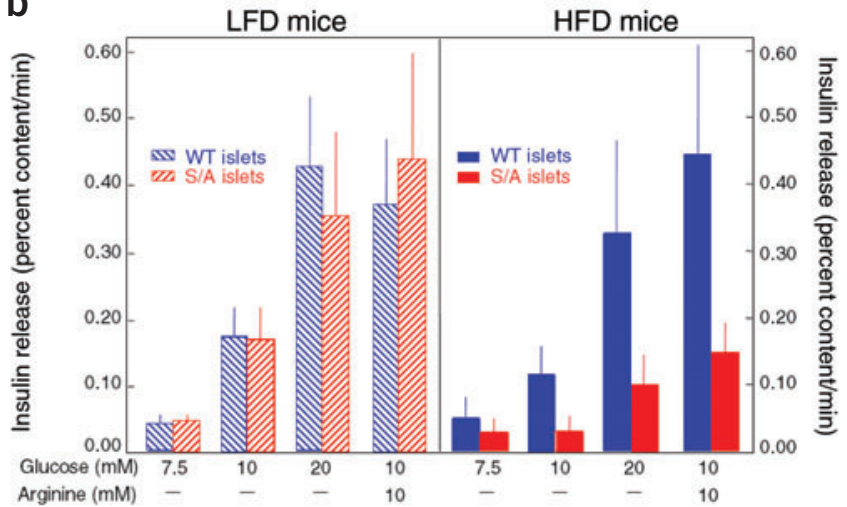

of mature insulin (Fig. 5a). In the islet extracts from wild-type LFD-fed mice, the majority of proinsulin was isolated under these conditions and processing of proinsulin to insulin efficiently occurred. In the islet extracts of HFD-fed Eif2s1 $1^{+/ \mathrm{tm} 1 \mathrm{Rjk}}$ mice, less 'free' (pro)insulin was detected and production of mature insulin was reduced. The fraction of processed insulin with respect to total insulin was $42 \%$ in islet extracts of LFDfed wild-type mice in contrast to $8 \%$ in HFD-fed Eif2s $1^{+/ \mathrm{tm} 1 \mathrm{Rjk}}$ mutant mice. Reversing the order of immunoprecipitation gave qualitatively similar results, indicating that HFD-fed Eif2s $1^{+/ \mathrm{tm} 1 \mathrm{Rjk}}$ beta cells contain a substantial pool of newly synthesized proinsulin that has an increased association with $\mathrm{BiP}$ (data not shown). As BiP is known to bind unfolded proteins ${ }^{36}$, we interpreted these differences as delayed folding and/or misfolding of proinsulin in the HFD-fed Eif2s $1^{+/ \mathrm{tm} 1 \mathrm{Rjk}}$ mutant islets.

\section{DISCUSSION}

Our findings show that a subtle reduction in eIF $2 \alpha$ phosphorylation leads to beta-cell failure and type 2 diabetes when the animals are stressed by a physiologically relevant HFD. In addition, these mice developed severe obesity that was associated with a reduced metabolic rate. The observation that eIF $2 \alpha$ phosphorylation regulates metabolism should catalyze a new direction of obesity research.

As obesity alone may be tolerated without progression to type 2 diabetes if beta-cell failure does not occur, our studies identify eIF $2 \alpha$ phosphorylation as an important mechanism for compensation and prevention of diet-induced diabetes. We showed that eIF $2 \alpha$ phosphorylation is necessary to prevent ER dysfunction and impaired insulin secretion when the demand for insulin is increased as a result of HFD. The beta-cell failure in this model shows the hallmarks of beta-cell demise in human diabetes in the following ways: the islets show elevated basal insulin secretion, diminished nutrient-stimulated insulin secretion, decreased insulin content per islet, an increased ratio of proinsulin/insulin and a reduced number of insulin-containing granules.

To compensate for a HFD and the associated peripheral insulin resistance, beta cells adapt to produce more insulin at the level of transcription, translation and secretion (Fig. 5b). Phosphorylation of eIF2 $\alpha$ may have a central role in this adaptive response through two mechanisms. First, although PERK-mediated eIF2 $\alpha$ phosphorylation inhibits general mRNA translation, it increases the translation of Atf4 mRNA, encoding a transcription factor that is required to induce the expression of genes encoding functions that increase the folding capacity of the $\mathrm{ER}^{37}$. This adaptive response may be compromised by the Eif2s $1^{\mathrm{tm} 1 \mathrm{Rjk}}$ mutation. In contrast to the beta-cell failure observed in PERK-null and Eif2s $1^{\mathrm{tm} 1 \mathrm{Rjk} / \mathrm{tm} 1 \mathrm{Rjk}}$ mutant mice, symptoms of beta-cell defects have not been observed in mice lacking the gene encoding ATF4 (ref. 38). Therefore, regulation of gene expression through eIF $2 \alpha$ phosphorylation as part of the UPR may not be the primary mechanism that facilitates beta-cell adaptation during compensation.

Figure 3 HFD reduces insulin secretion from perifused islets of Eif2s $1^{+/ t m 1 R j k}$ mice. Islets were isolated from male wild-type and Eif2s $1^{+/ t m 1 R j k}$ mice fed either a standard laboratory diet (a, left) or a HFD for 13 weeks (a, right), cultured overnight in HAM F10 medium containing $10 \mathrm{mM}$ glucose and perifused with a sequence of 10-min exposures to medium containing glucose ranging in concentration from basal $(3 \mathrm{mM})$ to $7.5,10$ and $20 \mathrm{mM}$. Between successive stimuli there were 15-min intervals of exposure to basal medium. During the last period of stimulation, $10 \mathrm{mM}$ glucose was added together swith $10 \mathrm{mM}$ arginine. Data represent means \pm s.e.m. ( $n=4-6$ experiments). (a) Time course of insulin secretion, expressed as percent of insulin content min. (b) Integrated release above basal for each individual stimulation from the same experiments as in a. Islets from HFD-fed Eif2s $1^{+/ \mathrm{tm} 1 \mathrm{Rjk}}$ mice secreted significantly less insulin than those from HFD-fed wild-type mice, multifactorial analysis of variance: $P=0.01$. WT, wild-type; S/A, Eif2s $1^{+/ \mathrm{tm} 1 \mathrm{Rjk}}$. 


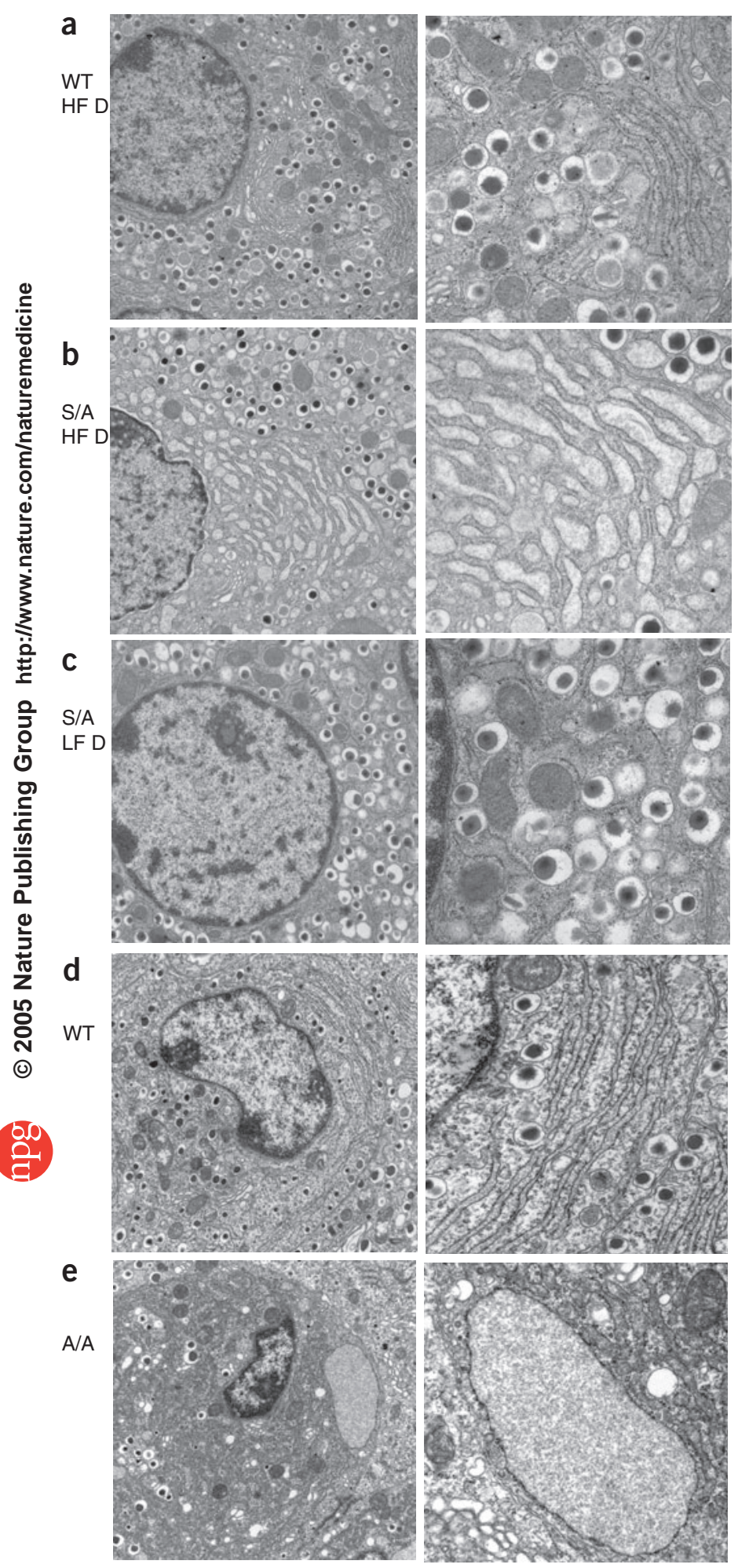

Alternatively, eIF2 $\alpha$ phosphorylation is essential to attenuate translation when the protein-folding load in the ER exceeds the protein-folding capacity. Because translation attenuation is partially defective in Eif2s $1^{+/ \mathrm{tm} 1 \mathrm{Rjk}}$ mice, unfolded proinsulin accumulates in the ER and inefficiently transits to the Golgi for processing and packaging into secretory granules (Fig. 5). To test this hypothesis, we analyzed ER structure and proinsulin biosynthesis and trafficking. Both a HFD and compromised eIF $2 \alpha$ phosphorylation
Figure 4 Beta cells of HFD-fed Eif2s $1^{+/ t m 1 R j k}$ animals have distended ER. (a-e) Electron micrographs are shown of ultra-thin sections $(70 \mathrm{~nm})$ of pancreas fixed with glutaraldehyde, post-fixed in $\mathrm{OsO}_{4}$ and stained with uranyl acetate and lead citrate. Animals were fed LFD or HFD for 20 weeks before isolation of pancreata. Beta cells from HFD-fed wild-type mice (a) have a normal ER appearance. The ER compartment of most beta cells from Eif2s $1^{+/ t m 1 R j k}$ HFD-fed animals becomes severely distended by accumulation of electron dense material (b). In comparison to wild-type littermate embryos (d), beta cells from Eif2s $1^{+/ t m 1 R j k}$ mice have a normal ER appearance when the animals are on a LFD (c). In comparison to wild-type littermate embryos

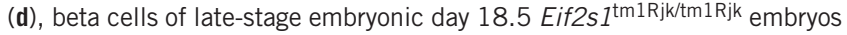
are reduced in number and show severe distension of the ER. In addition to distension, the ER often appeared darker with a heavy granular material (e). Magnification of left panels, $\times 7,900$; magnification of right panels, $\times 25,000$.

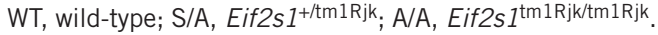

led to a substantial ER distension in beta cells, similar to that observed upon accumulation of unfolded proteins in the ER. In addition, a major proportion of proinsulin was detected in stable association with the protein chaperone $\mathrm{BiP}$ and was not processed to mature insulin. Given that $\mathrm{BiP}$ binds to proteins that are in an unfolded state, these findings suggest the combination of HFD and the Eif2s $1^{\mathrm{tm} 1 \mathrm{Rjk}}$ mutation establish conditions under which unfolded proinsulin accumulates. Proinsulin that cannot properly fold may be degraded through ER-associated degradation, possibly contributing to the reduced insulin content observed per islet. It is notable that HFD-fed wild-type mice also showed increased proinsulin association with $\mathrm{BiP}$, although to a lesser extent than the Eif2s $1^{+/ \mathrm{tm} 1 \mathrm{Rjk}}$ mutant mice. We propose that as beta cells compensate for insulin resistance, the increased translation of proinsulin exceeds the ER folding capacity and predisposes to beta-cell failure in type 2 diabetes. Under these conditions, PERK-eIF2 $\alpha$ signaling is required to preserve the structural and functional integrity of the ER. Recently, it was observed that a defect in XBP1, a component in another subpathway of the UPR, may contribute to insulin resistance ${ }^{39}$.It is notable that UPR-mediated translational regulation through PERK-eIF2 $\alpha$ is required to maintain insulin production and release whereas IRE1-XBP1 UPR signaling may be important to maintain insulin sensitivity.

Our findings suggest that genetic variation in genes regulating eIF $2 \alpha$ phosphorylation, as well as protein synthesis, folding, and ER quality control, including the UPR, may have an impact on beta-cell compensation and susceptibility to type 2 diabetes. Furthermore, therapeutic efforts designed to improve the efficiency of protein folding in the $\mathrm{ER}^{40}$ may protect from beta-cell overload and failure in type 2 diabetes.

\section{METHODS}

Eif2s $1^{+/ \mathrm{tm} 1 \mathrm{Rjk}}$ mice. The Eif $2 s 1^{+/ \mathrm{tm} 1 \mathrm{Rjk}}$ mice were generated as previously described ${ }^{27}$ and backcrossed for more than 10 generations with C57Bl/6J mice. We genotyped mice by PCR with oligonucleotides that flank the lox P NEO integration site, 5' oligomer: 5'-CACACACCCATTCCATGATAGTAAATG-3'; 3' oligomer: 5'-CAATGTTGTAGACCCTGACAATGAAGG-3'. All procedures were conducted according to protocols and guidelines approved by the University of Michigan Medical School, the Katholieke Universiteit Leuven and the Vrije Universiteit Brussel animal welfare committees.

High- and low-fat diet studies. Wild-type and Eif2s $1^{+/ \mathrm{tm} 1 \mathrm{Rjk}}$ mice (10-12 weeks old unless otherwise indicated) were housed pair-wise and provided either a LFD containing $10 \%$ fat or a HFD containing $45 \%$ fat (Research Diets Inc.) for up to 35 additional weeks. Wild-type littermate animals were used as controls in comparison to Eif2s $1^{+/ \mathrm{tm} 1 \mathrm{Rjk}}$ mice. We performed all studies with 6-12 mice per experimental group. We monitored body weight weekly. We analyzed food intake by measurement of food mass each day for $4 \mathrm{~d}$ and calculated intake (Kcal/d) using conversion rates of $3.85 \mathrm{Kcal} / \mathrm{g}$ for low-fat food and $4.73 \mathrm{Kcal} / \mathrm{g}$ for high-fat food. Measurements of body weight and food intake were taken at the same time each day. Animals were housed at $21-23{ }^{\circ} \mathrm{C}$ with 12 -hour light and dark cycles. Analysis of blood 
a

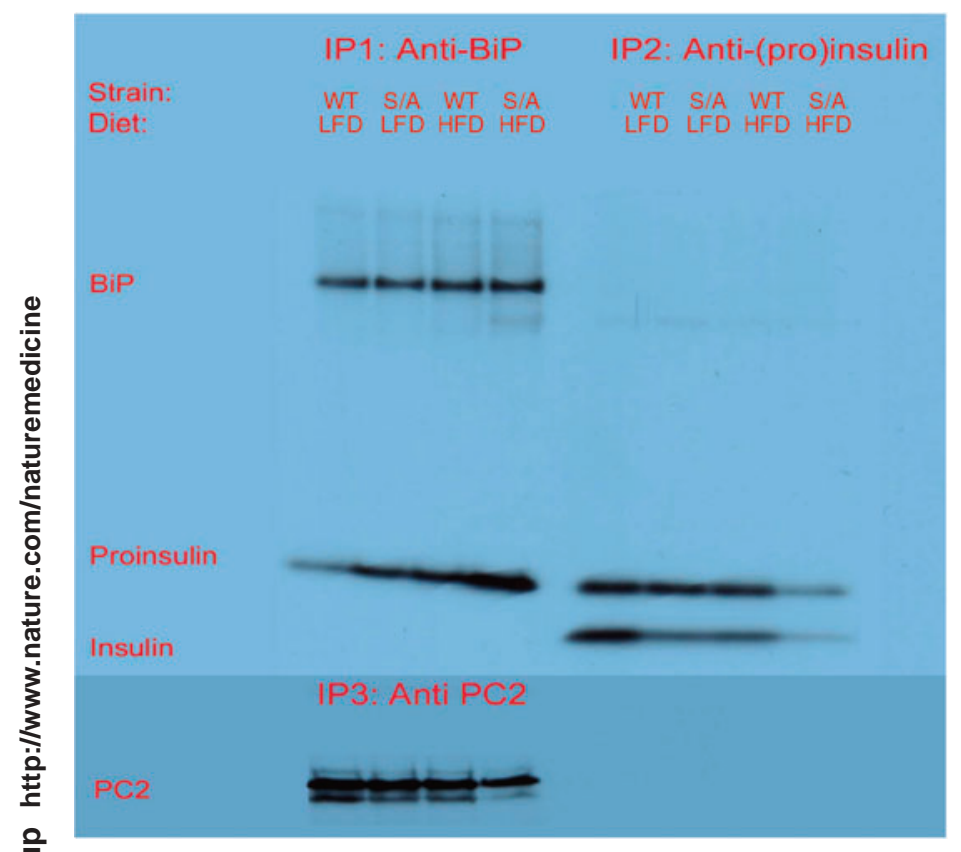

b

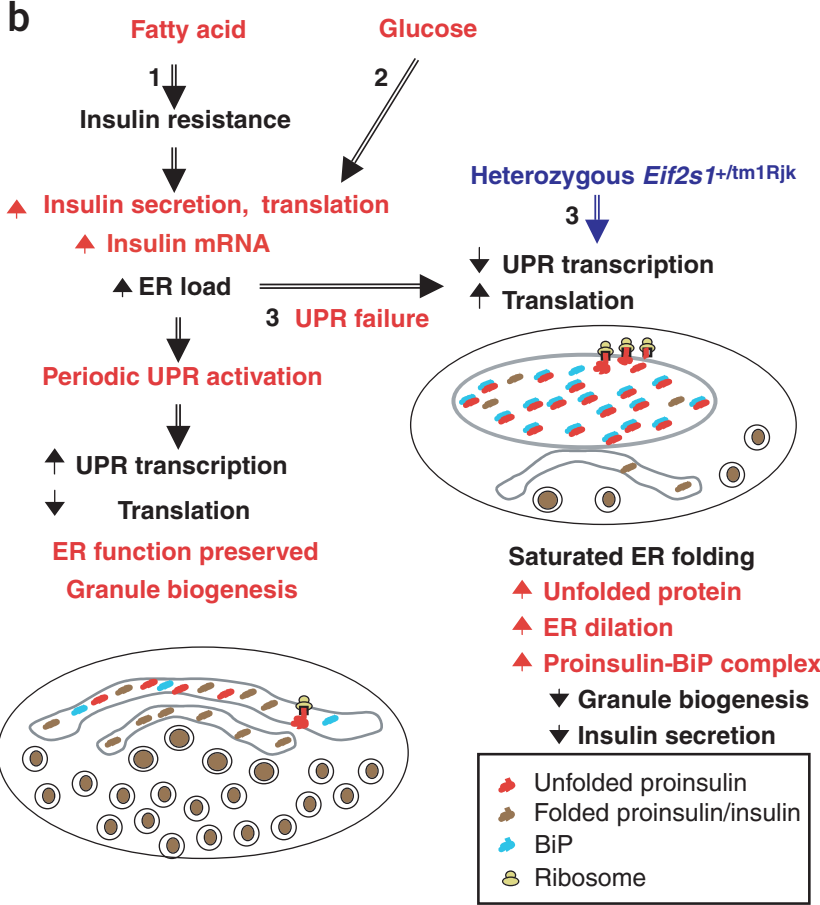

Figure 5 Combination of high fat and Eif2s $1^{\text {tm1Rjk }}$ mutation causes accumulation of proinsulin in the ER in beta cells. (a) Interaction between BiP and

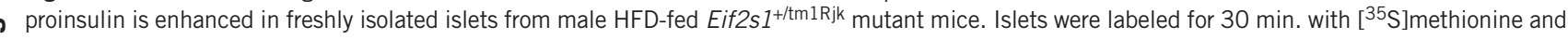
chased for $1 \mathrm{~h}$ at $10 \mathrm{mM}$ glucose, followed by immunoprecipitation with BiP-specific antibody. This results in coimmunoprecipitation of proinsulin bound to BiP. Subsequently, the supernatants from these reactions were immunoprecipitated with (pro)insulin-specific polyclonal antibody to detect free proinsulin and processed insulin. Quantification showed that $18 \%$ of unprocessed proinsulin was associated with BiP in islet extracts of LFD-fed wild-type animals whereas $76 \%$ was associated with BiP in extracts of HFD-fed Eif2s $1^{+/ t m 1 R j k}$ mice. The fraction of processed insulin/total was $42 \%$ in islet extracts of LFD-fed wild-type mice in contrast to $8 \%$ in HFD-fed Eif2s $1^{+/ t m 1 R j k}$ mutant mice. Immunoprecipitation of lysates with prohormone convertase 2 (PC2)-specific antibody detected no difference in the amount of islet material assayed. Representative autoradiogram of three independent experiments is shown. WT, wild-type; S/A, Eif2s $1^{+/ t m 1 R j k}$ genotype. (b) Proposed mechanism for saturated ER folding-mediated beta-cell failure in type 2 diabetes. During increased metabolic demand such as prolonged periods of increased glucose (pathway 2) or insulin resistance (pathway 1), the beta cells adapt by enhancing insulin mRNA abundance, proinsulin biosynthetic capacity and ER-folding capacity. There is a very delicate balance between proinsulin synthesis and ER folding capacity. Any alteration that disrupts this balance, such as genetic variation in the capacity to regulate translation, protein translocation, protein folding or the cellular response to unfolded protein, may result in the accumulation of unfolded proinsulin in the ER with a subsequent defect in secretory granule biogenesis. Our studies show that a $50 \%$ reduction in elF2 $\alpha$ phosphorylation results in accumulation of unfolded proinsulin and interferes with ER function (pathway 3). This in turn retards proinsulin maturation and granule biogenesis to contribute to the loss of nutrient-stimulated insulin release when metabolic demands are high, such as occurs after a HFD.

glucose, serum insulin, glucose and insulin tolerance, and leptin, cholesterol, triglycerides and fatty acids of the mice is described in Supplementary Methods online.

Isolation and culture of mouse pancreatic islets for perifusion studies. We isolated islets of Langerhans from wild-type and Eif2s $1^{+/ \mathrm{tm} 1 \mathrm{Rjk}}$ mice using collagenase (Boehringer Mannheim) as described ${ }^{33}$. Islets were hand-picked and studied either directly or cultured for $20 \mathrm{~h}$ in F10 medium Nutrient Mixture (HAM F10 medium; Gibco BRL, Life Technologies) containing $0.075 \mathrm{mg} / \mathrm{ml}$ penicillin, $0.1 \mathrm{mg} / \mathrm{ml}$ streptomycin, $0.5 \%$ (wt/vol) BSA (fraction V, RIA grade; Sigma), $2 \mathrm{mM}$ glutamine and $10 \mathrm{mM}$ glucose.

Measurement of insulin release. We measured insulin release using perifusion experiments in a multiple microchamber module (Endotronics) as described previously $^{33}$. Approximately 200 islets were loaded per Biogel P2 column and preperifused for 20 min in HAM F10 medium, supplemented with $0.5 \%$ BSA, $2 \mathrm{mM}$ glutamine, $2 \mathrm{mM} \mathrm{CaCl}_{2}$ and $3 \mathrm{mM}$ glucose, equilibrated with $95 \% \mathrm{O}_{2}$ and $5 \% \mathrm{CO}_{2}$. Flow rate was $0.5 \mathrm{ml} / \mathrm{min}$. At the end of the experiment, we extracted insulin content in $2 \mathrm{M}$ acetic acid, $0.25 \% \mathrm{BSA}$. We measured released and cellular insulin using radioimmunoassay. Release per minute was expressed as percent of islet insulin content. The total sum of secreted insulin during the whole experiment did not exceed $5 \%$ of the cellular content. We tested significance of differences between conditions by ANOVA.
Transmission electron microscopy. We fixed pancreatic tissue by immersion in $2.5 \%$ glutaraldehyde in $0.1 \mathrm{M}$ Sorensen buffer, post-fixed it in $1 \%$ osmium tetroxide, and en bloc stained it in 3\% uranyl acetate. The tissue was dehydrated in ethanol and embedded in Epon. We post-stained ultra-thin sections with uranyl acetate and lead citrate and examined them using a Philips CM100 electron microscope at $60 \mathrm{kV}$. Images were recorded digitally using a Kodak 1.6 Megaplus camera system operated using AMT software (Advanced Microscopy Techniques Corp.). Granule number, cytoplasmic area and ER area were quantified using Image Pro Plus. We counted granules with a visible insulin dense core.

Radiolabeling and immunoprecipitation of $\mathrm{BiP}$ and proinsulin. Islets were isolated as described above with modifications of injection of collagenase (Boehringer Mannheim; $4 \mathrm{mg} / 2.5 \mathrm{ml}$ salt buffer) into the common bile duct, digestion with shaking for $3 \mathrm{~min}$ at $37^{\circ} \mathrm{C}$, and dispersion by pipetting. We purified islets using three benchtop sedimentations and three selections by handpicking. Islets were preincubated in methionine-free RPMI-1640 medium (Sigma) for $1 \mathrm{~h}$ and then labeled in the same medium $(100 \mu \mathrm{l})$ containing $300 \mu \mathrm{Ci}\left[{ }^{35} \mathrm{~S}\right]$ methionine (Perkin Elmer; specific activity, $>1,000 \mathrm{Ci} / \mathrm{mmol}$ ) for $0.5 \mathrm{~h}$ at $37^{\circ} \mathrm{C}$, followed by a chase for $1 \mathrm{~h}$ in medium containing excess $(0.2 \mathrm{mM})$ unlabeled methionine. We then lysed the islets on ice for $10 \mathrm{~min}$ in $500 \mu \mathrm{llysis}$ buffer (50 mM Tris, $\mathrm{HCl}$ (pH 7.4), $150 \mathrm{mM} \mathrm{NaCl}, 1 \%$ Triton X-100, 0.1\% SDS, $1 \%$ sodium deoxycholate and protease inhibitors (Complete, Roche Diagnostics)). Islet lysates were precleared by centrifugation at $4{ }^{\circ} \mathrm{C}$ for $10 \mathrm{~min}$ at 15,000 r.p.m. 
in an Eppendorf centrifuge, followed by immunoprecipitation of the supernatant fluid $\left(2 \mathrm{~h}\right.$ at $4{ }^{\circ} \mathrm{C}$ ) using $10 \mu \mathrm{l}$ of BiP antiserum (provided by L. Hendershot ${ }^{41}$ ), insulin antiserum (provided by J. Hutton ${ }^{42}$ ) or PC2 antiserum ${ }^{43}$. Immune complexes were bound to $10 \mathrm{mg}$ of protein $\mathrm{A} / \mathrm{G}$ sepharose (GE Healthcare), washed twice by centrifugation with PBS, eluted from the sepharose using sample buffer, and analyzed by SDS-PAGE (Criterion, Bio-Rad). We performed densitometry of autoradiographic signals using Scion Image. We measured overall translation by $\left[{ }^{3} \mathrm{H}\right]$-tyrosine incorporation and precipitation of aliquots of the cellular extracts by trichloroacetic acid as described ${ }^{44}$.

\section{Note: Supplementary information is available on the Nature Medicine website.}

\section{ACKNOWLEDGMENTS}

We thank A. Saltiel for scientific guidance and manuscript review. We thank

O. MacDougald and $\mathrm{K}$. Longo for their input in characterizing the obesity

phenotype, including measurement of metabolic rates. We thank M. Pinter for technical assistance and her efforts in management of our mouse colony and diet studies. We also thank J. Mitchell for assistance with manuscript preparation. We thank D. Sorenson, S. Meshinchi and C. Edwards of the University of Michigan Microscopy and Image Analysis Lab and T. Pritchett of the Anatomical Pathology Department for technical and scientific contribution. This work was supported by US National Institutes of Health grant DK42394 (to R.J.K.) and grants from the Juvenile Diabetes Research Foundation (1-2002-801) and from the K.U. Leuven (grant GOA/2004/11) (to F.C.S.). J.C. is a postdoctoral fellow at the Flemish National Fund for Scientific Research (FWO-Vlaanderen). M.R. was supported by the US National Institute of General Medical Sciences (grant GM07767).

\section{AUTHOR CONTRIBUTION STATEMENT}

The laboratories of Frans C. Schuit and Randal J. Kaufman contributed equally to these studies.

\section{COMPETING INTERESTS STATEMENT}

The authors declare that they have no competing financial interests.

Received 4 November 2004; accepted 17 May 2005

Published online at http://www.nature.com/naturemedicine/

1. Zimmet, P., Alberti, K.G. \& Shaw, J. Global and societal implications of the diabetes epidemic. Nature 414, 782-787 (2001).

2. Maechler, P. \& Wollheim, C.B. Mitochondrial function in normal and diabetic beta-cells. Nature 414, 807-812 (2001).

3. Hinke, S.A., Hellemans, K. \& Schuit, F.C. Plasticity of the beta cell insulin secretory competence: preparing the pancreatic beta cell for the next meal. J. Physiol. (Lond.) 558, 369-380 (2004)

4. Itoh, N. \& Okamoto, H. Translational control of proinsulin synthesis by glucose. Nature 283, 100-102 (1980)

Schuit, F.C. In't Veld, P.A. \& Pipeleers, D.G. Glucose stimulates proinsulin biosynthesis by a dose-dependent recruitment of pancreatic beta cells. Proc. Natl Acad. Sci. USA 85, 3865-3869 (1988).

6. Wicksteed, B. et al. Cooperativity between the preproinsulin mRNA untranslated regions is necessary for glucose-stimulated translation. J. Biol. Chem. 276, 22553-22558 (2001).

7. Wicksteed, B., Alarcon, C., Briaud, I., Lingohr, M.K. \& Rhodes, C.J. Glucose-induced translational control of proinsulin biosynthesis is proportional to preproinsulin mRNA levels in islet beta-cells but not regulated via a positive feedback of secreted insulin. J. Biol. Chem. 278, 42080-42090 (2003).

8. Tillmar, L., Carlsson, C. \& Welsh, N. Control of insulin mRNA stability in rat pancreatic islets. Regulatory role of a $3^{\prime}$-untranslated region pyrimidine-rich sequence. J. Biol. Chem. 277, 1099-1106 (2002).

9. Knoch, K.P. et al. Polypyrimidine tract-binding protein promotes insulin secretory granule biogenesis. Nat. Cell Biol. 6, 207-214 (2004).

10. Alarcon, C., Lincoln, B. \& Rhodes, C.J. The biosynthesis of the subtilisin-related proprotein convertase $\mathrm{PC} 3$, but no that of the PC2 convertase, is regulated by glucose in parallel to proinsulin biosynthesis in rat pancreatic islets. J. Biol. Chem. 268, 4276-4280 (1993).

11. Webb, G.C., Akbar, M.S., Zhao, C. \& Steiner, D.F. Expression profiling of pancreatic beta cells: glucose regulation of secretory and metabolic pathway genes. Proc. Natl Acad. Sci. USA 97, 5773-5778 (2000).

12. Dever, T.E. Gene-specific regulation by general translation factors. Cell 108, 545-556 (2002).

13. Han, A.P. et al. Heme-regulated elF2alpha kinase (HRI) is required for translational regulation and survival of erythroid precursors in iron deficiency. EMBO J. 20, 6909-6918
(2001).

14. Kaufman, R.J. Double-stranded RNA-activated protein kinase mediates virus-induced apoptosis: a new role for an old actor. Proc. Natl Acad. Sci. USA 96, 11693-11695 (1999).

15. Dever, T.E. et al. Phosphorylation of initiation factor 2 alpha by protein kinase GCN2 mediates gene-specific translational control of GCN4 in yeast. Cel/ 68, 585-596 (1992).

16. Harding, H.P., Zhang, Y. \& Ron, D. Protein translation and folding are coupled by an endoplasmic-reticulum-resident kinase. Nature 397, 271-274 (1999).

17. Zhang, K. \& Kaufman, R.J. Signaling the unfolded protein response from the endoplasmic reticulum. J. Biol. Chem. 279, 25935-25938 (2004).

18. Kozutsumi, Y., Segal, M., Normington, K., Gething, M.J. \& Sambrook, J. The presence of malfolded proteins in the endoplasmic reticulum signals the induction of glucoseregulated proteins. Nature 332, 462-464 (1988).

19. Dorner, A.J., Wasley, L.C. \& Kaufman, R.J. Increased synthesis of secreted proteins induces expression of glucose-regulated proteins in butyrate-treated Chinese hamster ovary cells. J. Biol. Chem. 264, 20602-20607 (1989).

20. Morris, J.A., Dorner, A.J., Edwards, C.A., Hendershot, L.M. \& Kaufman, R.J. Immunoglobulin binding protein (BiP) function is required to protect cells from endoplasmic reticulum stress but is not required for the secretion of selective proteins. J. Biol. Chem. 272, 4327-4334 (1997).

21. Bertolotti, A., Zhang, Y., Hendershot, L.M., Harding, H.P. \& Ron, D. Dynamic interaction of BiP and ER stress transducers in the unfolded-protein response. Nat. Cell Biol. 2 326-332 (2000)

22. Delepine, M. et al. EIF2AK3, encoding translation initiation factor 2-alpha kinase 3 , is mutated in patients with Wolcott-Rallison syndrome. Nat. Genet. 25, 406-409 (2000).

23. Senee, V. et al. Wolcott-Rallison Syndrome: clinical, genetic, and functional study of EIF2AK3 mutations and suggestion of genetic heterogeneity. Diabetes 53, 1876-1883 (2004).

24. Harding, H.P. et al. Diabetes mellitus and exocrine pancreatic dysfunction in perk-/-mice reveals a role for translational control in secretory cell survival. Mol. Cel/7, 1153-1163 (2001).

25. Yang, Y.L. et al. Deficient signaling in mice devoid of double-stranded RNA-dependent protein kinase. EMBO J. 14, 6095-6106 (1995).

26. Zhang, P. et al. The GCN2 elF2alpha kinase is required for adaptation to amino acid deprivation in mice. Mol. Cell. Biol. 22, 6681-6688 (2002).

27. Scheuner, D. et al. Translational control is required for the unfolded protein response and in vivo glucose homeostasis. Mol. Cel/ 7, 1165-1176 (2001).

28. El-Haschimi, K., Pierroz, D.D., Hileman, S.M., Bjorbaek, C. \& Flier, J.S. Two defects contribute to hypothalamic leptin resistance in mice with diet-induced obesity. J. Clin. Invest. 105, 1827-1832 (2000)

29. Pelleymounter, M.A. et al. Effects of the obese gene product on body weight regulation in ob/ob mice. Science 269, 540-543 (1995).

30. Bachman, E.S. et al. betaAR signaling required for diet-induced thermogenesis and

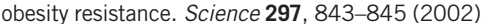

31. Nakae, J. et al. The forkhead transcription factor Foxol regulates adipocyte differentiation. Dev. Cell 4, 119-129 (2003)

32. Williams, B.R.G. Signal Integration via PKR. (Science's STKE, 2001).

33. Flamez, D. et al. Mouse pancreatic beta-cells exhibit preserved glucose competence after disruption of the glucagon-like peptide-1 receptor gene. Diabetes 47, 646-652 (1998).

34. Jorns, A., Munday, R., Tiedge, M. \& Lenzen, S. Comparative toxicity of alloxan, N-alkylalloxans and ninhydrin to isolated pancreatic islets in vitro. J. Endocrinol. 155, 283-293 (1997).

35. Bergsten, P., Grapengiesser, E., Gylfe, E., Tengholm, A. \& Hellman, B. Synchronous oscillations of cytoplasmic $\mathrm{Ca} 2+$ and insulin release in glucose-stimulated pancreatic islets. J. Biol. Chem. 269, 8749-8753 (1994).

36. Gething, M.J. \& Sambrook, J. Protein folding in the cell. Nature 355, 33-45 (1992).

37. Lu, P.D. et al. Cytoprotection by pre-emptive conditional phosphorylation of translation initiation factor 2. EMBO J. 23, 169-179 (2004).

38. Yang, X. et al. ATF4 is a substrate of RSK2 and an essential regulator of osteoblast biology; implication for Coffin-Lowry Syndrome. Cell 117, 387-398 (2004).

39. Ozcan, U. et al. Endoplasmic reticulum stress links obesity, insulin action, and type 2 diabetes. Science 306, 457-461 (2004).

40. Boyce, M. et al. A selective inhibitor of elF2al pha dephosphorylation protects cells from ER stress. Science 307, 935-939 (2005).

41. Lee, Y.K., Brewer, J.W., Hellman, R. \& Hendershot, L.M. BiP and immunoglobulin light chain cooperate to control the folding of heavy chain and ensure the fidelity of immunoglobulin assembly. Mol. Biol. Cell 10, 2209-2219 (1999).

42. Grimaldi, K.A., Hutton, J.C. \& Siddle, K. Production and characterization of monoclonal antibodies to insulin secretory granule membranes. Biochem. J. 245, 557-566 (1987).

43. Creemers, J.W. et al. Identification of a transferable sorting domain for the regulated pathway in the prohormone convertase PC2. J. Biol. Chem. 271, 25284-25291 (1996).

44. Schuit, F.C., Kiekens, R. \& Pipeleers, D.G. Measuring the balance between insulin synthesis and insulin release. Biochem. Biophys. Res. Commun. 178, 1182-1187 (1991). 